\title{
Examining Strategic Human Resource Management and Organizational Effectiveness in Pakistani Organizations
}

\author{
Khurram Jawad Khawaja \\ MS Scholar \\ University of Management and Technology Lahore Pakistan \\ Email: kjkhawaja_5sr@yahoo.com
}

Professor Dr. Sarwer Azhar
Director PhD \& Centre for Graduate Research
University of Management and Technology Lahore Pakistan
Email: sarwar.azhar@umt.edu.pk
Attique Arshad (Corresponding Author)
MS Scholar
University of Management and Technology Lahore Pakistan
Email: attique126@ gmail.com

Doi:10.5296/ijhrs.v4i3.5992ＵRL: http://dx.doi.org/10.5296/ijhrs.v4i3.5992

\begin{abstract}
Purpose

SHRM is facing potential theoretical challenge in terms of unveiling "black box" mystery lies between logical and strategic application of SHRM and its impact on organizational effectiveness. To explore the gap between HR contribution and competitive advantage gained by the organizations, a viable mediating framework is needed in SHRM.
\end{abstract}

\section{Design/Methodology/Approach}

In the awake of rising world interest in SHRM, this paper aimed to analyze the scholarly works on SHRM those offer to stimulate mechanisms and configurations through which SHRM can serve to improve organizational effectiveness. Outcome of the debate is likely to use in future empirical research.

\section{Findings}

Organization needs to distinguish itself in performance and strategy from the other organizations. Improvement in resources helps the organizations to gain competitive advantage. Resource-based view of the firm used as a lens for this study explains that difference in business's performance is dependent upon resources owned by the business. This study attempts to offer a framework that proposes a strategy to distinguish itself in performance. HRM management set up in an organization gets influenced by HR system, and practices prevalent in the organization, workforce skills, employee level of competence, employee commitment and engagement. An organization cannot remain aloof from the 
repercussions of extraneous conditions such as political, economic, sociological, technological, legal and environment.

\section{Limitations and Future Research Directions}

This conceptual study is limited to state and status of strategic HRM activities in Pakistani organizations. Future study may conduct empirical research by including employee perceptions as unit of analysis at the province level.

\section{Practical Implications}

The study is of great value to Pakistani organizations to excel on organizational effectiveness to optimize financial performance. This study offers a practical and rudimentary framework to implement desired strategic human resource management to gain organizational effectiveness.

\section{Key words}

SHRM, organizational effectiveness, Pakistan, framework

\section{Introduction}

The efforts, skills, and capabilities acquired by the people to serve their organization make them human resources (Appleby \& Mavin, 2000). Achievement of organizational goals and objectives through systematic and planned positioning of human resources is referred to as SHRM (Wright, P. M., \& McMahan, G. C. (1992). Shoots of SHRM find their development in the mid of twentieth century. A company where human resource management role must fit in the planning process, it strives to make it strategic (Van Donk, D. \& Esser, A,,2001)

This research aimed to target major conceptual issues relating to strategic human resource management for debate and analysis. In the awake of rising world interest in SHRM, this paper aimed to analyze the scholarly works on SHRM to stimulate mechanisms and configurations through which SHRM can serve to improve organizational effectiveness. Outcome of the debate will likely to use in future empirical research. SHRM is facing potential theoretical challenge in terms of unveiling "black box" mystery lies between logical and strategic application of SHRM application and its impact on organizational effectiveness. To explore the gap between HR contribution and competitive advantage gained by the organizations, a viable mediating construct is needed in SHRM. In order to check the strategy implementation, goodness of fit and synergy between the human resource architecture, strategic capacity and organizational processes is must to explore. This means, a distinct ' $\mathrm{HR}$ architecture' will play decisive role inside and between the companies (Lepak \& Snell, 1999). Strategy implementation and estimating HR impact on company' performance has emerged as formidable areas to explore in future studies. This provides theoretical base and new directions in research on SHRM.

In the next section, the state and status of SHRM practices will be discussed at length to generate new perspectives on the area.

\section{Strategic human resource management; view point}

SHRM has four distinctive periods of the research: Period from 1980-1990 belongs to conceptual research undertaken by researchers. Period from 1990-2000 witnessed 
universalistic, configurational and context classification. During the period from 2000-2005, the proposal of HR architecture was proposed. The year 2005 onward shifted focus on organizational performance as a result of HRM activities in the area of SHRM. SHRM looks for more implementation instead of formulation. HR management is concerned with individual performance whilst SHRM deals with organizational performance. This means focus of strategy is to get financial advantage. HR management is entrusted to solve day to day business problems whereas it is expected from SHRM to create 'above average financial performance'. Therefore, HR management set up and financial performance is depicted through SHRM model. HR management includes HR system, practices, workforce skills, and level of competences and employee commitment and engagement to performance (Brian E. Beckar and Mark A. Huselid, 2006). A study on SHRM examined similarity among strategy and policy of organizations, HRM practices and higher performance acquired by the organizations (Chadwick and Cappelli 1999).

SHRM is not confined to hiring people. There is much beyond it. Speculation about SHRM is mainly due to dearth of conceptual knowledge about SHRM, lack of a strong theoretical model and integrated framework of strategic human resource management (Qamar Ali and Muhammad Zafar Iqbal Jadoon, 2000 ) Despite having dissimilar definitions, SHRM has a common construct that people are human capital and to acquire and maintain competitive advantage, human assets need to be managed effectively (Dulebohn, J. G., 1995). Efficacy of SHRM results in reducing employee turnover and augments market performance. Change in performance, and return on investing in human resource are the outcome of SHRM effectiveness (Richard, O.C. \& Johnson, 2004).

The framework begins with a set of HR system, practices, workforce skills, level of competences and employee commitment and engagement combine to propose a strategy for implementation to gain financial performance. All these elements combine to form strategic human resource management. According to Pestle model, conditions enumerated above leave their influence on SHRM phenomenon. 'Above average financial performance' is closely related to HR administrative set up and strategic handling of human resource. HR hierarchal set up reflect the strategic value creation. Besides value creation, HR system has the potential to align with company's strategy. Locus of value creation and inimitability matters most in SHRM (Wright, Dunford, \& Snell, 2001). HR system is therefore, most important strategic asset. Literature on SHRM reveals that there has been little research on the implications of SHRM theory in a way to impact company's firm by integrating its different processes (Becker, B. E., \& Huselid, M. A., 2006). According to a study conducted by Gerhart (2005) identified that SHRM emphasizes to find impact of HR on employee relations and attitudes. In this way, effects of SHRM trickle down to individual level.

SHRM is abounding with different perspectives to explore the value and importance of HRM. Two important models popularly represent the field of SHRM. One is best fit contingency model that lays the need to integrate HR strategy with organizational and environmental context in order to make it more effective (Boxhall and Purcell (2000: 186). HR activities must configure each other 'internally' and the competitive environment and strategy 'externally' (Baird and Meshoulam, 1988). The other model that is known as 'best practice' Universalist model emphasize that organizations can be expected better outcomes in case 
they resort to adopt the best HR practices (Pfeffer and Veiga, 1999). These researchers offered a set of seven best practices (job security, selective hiring, extensive training, high compensation, self-managed teams, information sharing and reduction of status), another research identified four type of HR practices including information, training, remuneration and empowerment (Lawler, 1992). An empirical research concluded with another set of human resource practices i.e. training, empowerment, high wages, performance-based compensation, collective participation and skill development (Arthur,1994) ) and Wood and de Menezes' (1998) included recruitment, appraisal systems and job security to Arthur's (1994) list. These works laid the foundation of high performance work systems (HPWS) using HR practices premeditated to increase employees' skills, commitment and performance (Datta et al., 2005). According to Pfeffer and Veiga, (1999), the practices referred to above have universal application and found successful (Pfeffer and Veiga, 1999). Both the perspectives hold their distinct positions on effectiveness of HRM practices and strategic importance of SHRM yet there is a consensus that human resources are the real source of competitive advantage that is the core foundation of SHRM. The existing studies on SHRM are based on "tick box" survey researches. These studies could not take into account employee experience and role of certain 'contingency' factors behind shaping employee perception about the questions asked (Truss, 2001).

HR Departments in Pakistani organizations are unable to create awareness and trends about human resource management and maintaining documentation procedures (Shaista E. Khiiji and Xiaoyun Wang, 2006). The study is of great value to Pakistani organizations to excel on organizational effectiveness to optimize performance. This is to know whether organizations are able to implement the intended SHRM philosophy on attaining desired human performance (Khalid, M. M., Ashraf, M., 2011) or there exists any gap between intended and implemented.

It is vital to acknowledge that HR hierarchal structure must be differentiated in strategic capabilities in a company. Porter called it strategic value of differentiation by holding strategic positioning. He emphasized upon attaining strategic value through differentiation performance by performing same activities in a different manner instead of seeking 'best practices' or 'universalistic approach' for developing HR strategy. Proponents of contingencies theory on SHRM believe that every organization needs to develop its unique strategy fit for itself at right time (Zajac, Kraatz, and Bresser, 2000). The role of contingency theory to HR strategy can be used in future researches. So far, debate on our thinking on SHRM has given us a shift in previous thought on best practice hunting (Becker \& Huselid, 1998) as HR strategy to focus on workforce investment by adopting differentiation in practices and policies.

However, many still believed that company would continue to look for building high performance system through either high practices or quality in HR management. In order to get real strategic opportunity, companies would lay high emphasis on contingencies and differentiation but with equilibrium between the both. Porter (1985) found HRM a great source of acquiring competitive advantage through minimizing costs and adding differentiation. If required both measures can be applied. To achieve this milestone, HRM activities must be 
accomplished strategically. Therefore, competitive use of human resources to get strategic objectives of the company is the subject of SHRM.

SHRM is beneficial in the awake of company's strategy needs. It lies to study the costs associated. SHRM may relate to the areas of showing concern about commitment to employees for their job security and work load (Khalid, M.M., Ashraf, M., Azeem, M., Ahmed, R.I, and Ahmad, H.N. (2012), allocating balanced proportionate financial resources to human resource activities, taking special care for employees according to market realities, removing complexity of decision making (Khalid, M.M., M., Ilyas, and C.A. Rehman 2014) and so on. Many scholars believe that if an organization is able to deploy HRM practices having mutual compatibility, the scope of SHRM and its impact on organizational effectiveness will be at its zenith. This can draw the best outcomes in the shape of achievement of organizational aspirations and goals(Khalid, M. M., Ashraf, M., \& Rehman, C. A., 2012). Some opined that if organizations successfully deal with external and internal challenges by deploying 'the human capital and HRM practices', they can aspire for the best impact of SHRM on organizational effectiveness. That is why organizations are more prone to imitate one's HR practices to ensure the chances of success (Lengnick-Hall, and Lengnick-Hall 1988).

Using the above debate, the study resorts to prove whether effectiveness of SHRM strategy and practice considerably affect organizational outcomes. The significance of SHRM has been acknowledged as a potential source of winning financial advantage for any organization (McMahan, G. C., Bell, M. P., \& Virick, M., 1998). Technical advantage acquired by the organizations in terms of strategic positioning (Khalid, M.M., Ashraf, M., Azeem, M., Ahmed, R.I, and Ahmad, H.N., 2012), pre-emption before actual win, differentiation in activities and growth strategy (Khalid, M. M., Ashraf, M., 2011) produces varieties to satiate all stakeholders and determine effectiveness of organizational performance in the market place. Effectiveness of organizational performance embarks on to win sustainable strategic position that demands 'trade-off' to acquire financial viability (Abbas, R. Z., Ashraf, M., \& Alam, H. M., 2011)

Research literature on SHRM provides new insights to adopt proactive management to address constantly evolving issues in right direction (Kelly \& Amburgey, 1991). In order to formulate a strategy, organizations must assess the extraneous circumstances to evaluate information and opportune factors present in the respective country's environment (Hunger \& Wheelen, 2003). To cover different dimension of strategic human resource management for this study, elements found in Pakistani context were taken into account:

\section{Laws and regulations:}

Labor laws of Pakistan are inherited from Indian Act. To meet these challenges, Pakistan government has launched various labor policies, right from its independence to emulate the transformations in governance from dictatorship to democracy. In Pakistan, labor is the subject of both federal and provincial governments. Federal government enacts the law and also demand from the provincial government to frame their own labor laws configured with their local conditions. Pakistan ranks among the $10^{\text {th }}$ largest nation in the world having $32.8 \%$ of the 
participated labor force. Population of labor force is about 53.72 million (Labor force survey 2008-09 Pakistan). Laws are available in Pakistani but implementation is sluggish that is the basis of low performance (Khalid, M.M., M., Ilyas, and C.A. Rehman 2014). Any model aspired to deal with SHRM in Pakistani context has to identify the black holes in the implementation of the labor laws.

\section{Culture:}

Pakistan is a moderately masculine society with power distance prevailing in nook and corner of the country. According to Hofstede (2002) on Pakistani cultural differences, Pakistan scores 50 out of 100 in power distance index (PDI). In the context of power variable, Pakistan scores $10 / 100$ in individualism which shows Pakistani society as a highly collectivist society. This is in major contrast to US society that carries highly individualistic perspective.. Hence model apparently operationalized in US can not necessarily be useful in Pakistan. Here frameworks should be developed taking into account the collective conditions prevailing in the society. Geert Hofstede (2002) contributes valuable information to the body of knowledge in the area of SHRM. In this background, power variable must be mentioned in the proposed SHRM framework for Pakistan. Pakistan scores 10/100 in individualism which means this is a highly collectivist society as opposed to US which is highly individualistic society, hence supporting the fact that any model useful in US can not necessarily be useful in Pakistan. Here frameworks should be developed taking into account the collectivism prevailing in the society. Pakistani society is often considered change resistant and ill responsive to innovation. That is why it remains afflicted with uncertain conditions. On uncertainty avoidance table, Pakistan scores 70 out of 100. In this environment, to adopt a SHRM model is a real challenge. Pakistan however, needs a vibrant and practical SHRM model to understand the human resource management phenomenon carefully.. Society is being run on adhocism and there is a great scope of application for any SHRM model.

\section{Politics:}

Social and organizational life in Pakistan is overwhelmingly polluted by immoral politics. Word politics is carried by a tag of lies, nepotism, favoritism, jobbery and corruption. This terminology_has engulfed the social and organizational life in Pakistan and now has become a symbol of recognition of our society in the world. A tangible endeavor is required in building a SHRM framework to monitor and control unfair endeavors in politics and bring fair practices. This will improve scenario in organizations and society as well.

\section{Unions:}

Citizenry of Pakistan has the right of association under the constitution of Pakistan. Employees working everywhere are allowed to join any union of their choice. Employers and unions shall have the right to join alliances and get allied with any other workers' Unions or alliance on country wide basis. They can join any set up and amalgamate. Under the provisions of IRO (Industrial relations ordinance), employee can elect their representative trade union Collective Bargaining Agent (CBA) through secret ballot. CBA represents employees in industrial disputes and in committees, boards and commissions. Though constitution of the country allows legal authorization and in the awake of privatization, 
currently, legislative activities relating to trade unions is implemented least and the legal practice of trade unions is extensively depressed in different industries.

\section{The resource-based view (RBV)}

This theory provides an optimum rationale to utilize the potential and strategic role of humans as assets for their respective company (Wright \& McMahan, 1992). Organizations can win competitive financial advantage and above average performance until these give human resources as strategic importance. RBV tends to integrate development of internal resources (employee characteristics) and strategic resources. A resource that has the capacity to implement strategies gets competitive advantage (Barney, 2001:54). Implementation needs to be given importance in SHRM. Link between HRM and company' performance is affected or facilitated through or by many intermediary outcomes (Becker \& Gerhart,1996). A company' strategic capability serves as a key intermediate variable to operationalize company's strategy. Literature on RBV highlights two terms 'resources' and 'capability' referring to tangible and intangible assets deployed by the companies to develop and implement their strategies (Ray, Barney, \& Muhanna, 2004:24). Capabilities relate to firm specifically and become a part of the firm resource management. Development of other resources will serve as 'intermediate goods' (Amit \& Shoemaker, 1993). These intermediate goods contribute to explain the 'black box' myth between HR management and company performance. Mainstay of RBV theory is 'resources' and 'capabilities'. Porter however, emphasized on 'activities'. SHRM related literature gives an account of 'market positioning'. It is argued that strategy execution capability propounded by RBV plays a decisive role in developing SHRM framework. Integrating strategy execution capability with SHRM policy of the company provided vital links to strategy implementation (Wright, P. M., \& Sherman, W. S., 1999). Strategy execution capability provides directional approach in extending SHRM approach embodying "set of specific and identifiable processes, such as product development, strategic decision making and alliancing."(Eisenhardt and Martin, 2000: 1106). Ray et al., (2004) defines business processes "are the way that the competitive potential of a firm's resource and capabilities are realized and deserve study in their own right." In the light of these arguments, it can be deduced that strategic business processes are the desirable intermediate outcomes that play best in strategy implementation. That is why, RBV aimed to test business processes effectiveness as dependent variable instead of company' performance.

While examining the effective use of human resources on organizational performance, the resource-based view of the firm was analyzed as a lens. Resource based view (RBV) has far reaching effects for SHRM. It urges the researchers to elevate their conceptual thinking about human resources as viable internal assets of organizations and serve as a promoter to gain and sustain advantage for organizations (Barney 1986). The Resource Based View (RBV) provides an "inside-out" approach to seek trade-off among different resources and embarks on the organization indigenous resources and capabilities to develop sustainable competitive advantages. To RBV, resources make the organizations capacitated to improve their performance. Human resources bear the vital potential out of all resources at the disposal of the organization. Ability and motivation of humans lead towards performance. In other words, 


\section{Macrothink

competence and behavior of employees is the key to performance. Competency converts human resources into human capital. It is the attitude that serves as a catalyst to convert wavered human potential into competitive advantage.

Organizations have strategic options in terms of their resources. These resources create position barriers and block the growth of rival products at the entry level in the market place. In fact organizations aspire for development of such position barrier products. It would be worthwhile to mention here that RBV considers products as 'resources' those are produced jointly with products. RBV theory suggests strong findings that there is a dire need of a framework that could address the performance needs of the organizations. At this juncture, PESTLE model acknowledged that a business organization can not dissuade from the extraneous conditions such as political, economic, sociological, technological, legal and environmental conditions dominant in respective country. Peace and security, GDP growth scenario, culture, technological environment, legal rights situation and environmental protection or ignorance circumstances. This conceptual paper seeks to propose a SHRM framework from the works of Brian E. Beckar and Mark A. Huselid, 2006 and implications of PESTLE model. 
This perspective is summarized in the following framework:

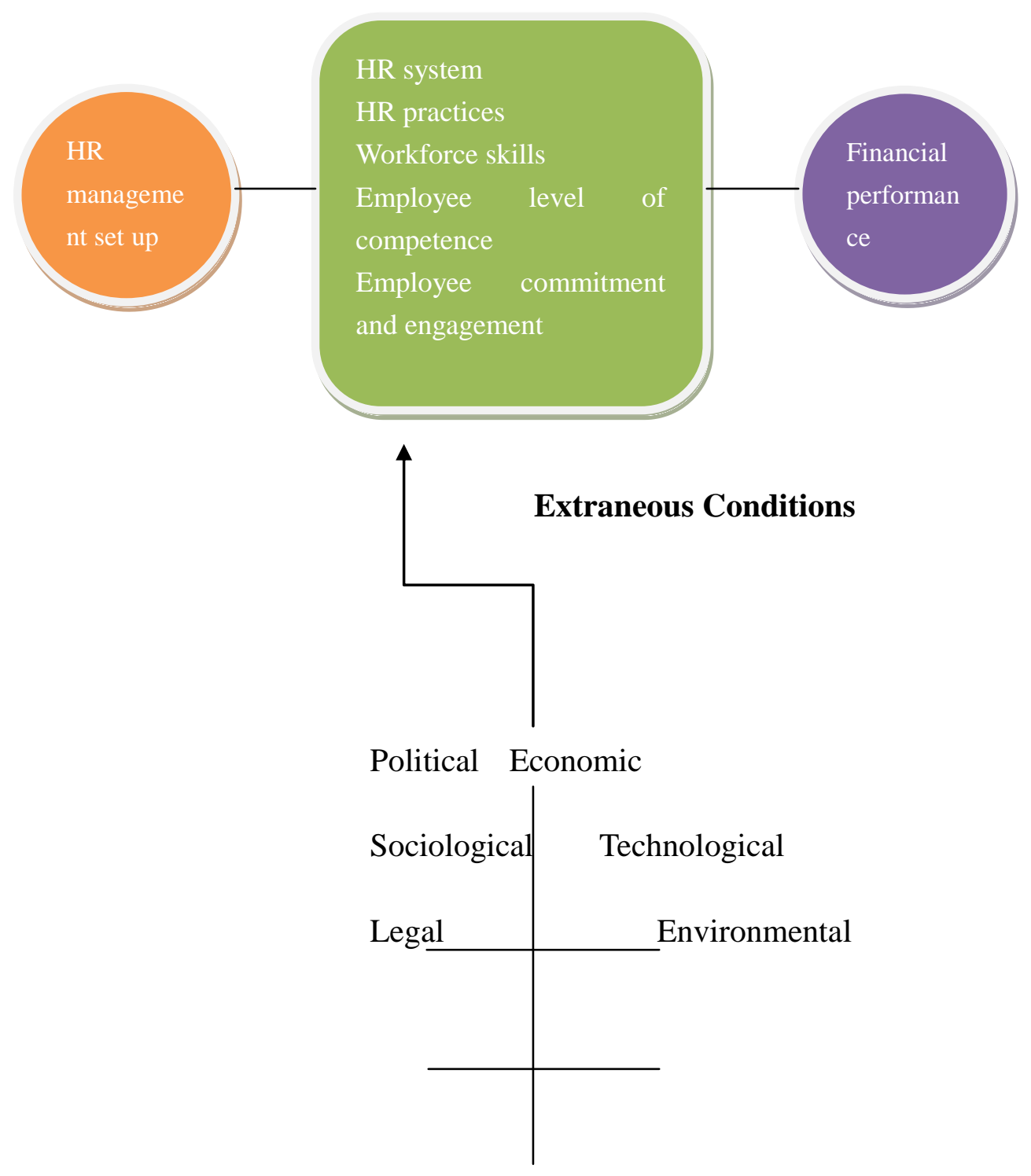

Conceptual Framework 


\section{Al Macrothink

\section{Commentary on the aforesaid framework}

This study attempts to offer a framework that proposes a strategy to distinguish itself in performance. HRM management set up in an organization gets influenced by HR system, and practices prevalent in the organization, workforce skills, employee level of competence, employee commitment and engagement. By adhering to this set of human resource management set up, an organization can aspire desired financial performance. In developing nations, more emphasis is given to optimize revenue for growth and sustenance of business. Hence financial performance is the life line of an organization. An organization cannot remain aloof from the repercussions of extraneous conditions such as political, economic, sociological, technological, legal and environment. A successful organization is required to take into account all these internal (HR management set up) and external factors (PESTLE) to face spiral business events and changes successfully.

\section{Conclusion}

In the new millennium, businesses face spiral business events and changes. Extraneous conditions put further burden and more challenges on business organizations. Competition has gone beyond domestic borders and touched international horizon. In these conditions, organization needs to distinguish itself in performance and strategy from the other organizations. Improvement in resources helps organizations to gain competitive advantage. Resource-based view of the firm used as a lens for this study explains that difference in business's performance is dependent upon resources owned by the business.

Organizations are therefore, not supposed to contend with extant competencies. They need to look for newer. Exploring SHRM provided new insights to adopt preemptive measures to address constantly evolving management issues at right time. Organizations in Pakistan need to develop more and more case study inquiries to better improve the stagnant processes. Scholars must research carefully between exploitation and exploration of resources for improvement in performance at individual and organizational level. To formulate a strategy, organizations must assess the extraneous circumstances to control uncertainty and enhance organizational effectiveness. In future, organization must understand how to cope with drastic changes in technology and environment as well. Laws and regulations, culture, politics, unions, labor markets, and industry characteristics were discussed in the context of Pakistan. Different directions were explored to develop an indigenous model of SHRM in Pakistan.

This paper conducted conceptual work on theoretical relationship about the "black box" myth between HR management and company performance. Future studies may lay more emphasis on probing inside the "black box" within the HR structure. 


\section{References}

Appleby, A., \& Mavin, S. (2000). Innovation not imitation: human resource strategy and the impact on world-class status. Total Quality Management, 11(4-6), 554-561.

Abbas, R. Z., Ashraf, M., \& Alam, H. M. Mirror up to leadership and Strategic Human Resource Management: An Exploratory Account. Interdisciplinary Journal of Contemporary Research in Business 2.10 (2011).

Ali, Q., \& Jadoon, M. Z. I. Adaptability of SHRM in the Context of Pakistan. International Journal of Management \& Organizational Studies VOLUME 1, ISSUE 1.

Amit R., Schoemaker P., (1993), 'Strategic assets and organizational rent', Strategic Management Journal, 14, 33-46

Arthur, J. B. 1994. "Effects of human resource systems on manufacturing performance". Academy of Management Journal, 37: 670-687

Baird, L., \& Meshoulam, I. (1988). Managing two fits of strategic human resource management. Academy of Management review, 13(1), 116-128.

Barney, J. B. (1986). Organizational culture: can it be a source of sustained competitive advantage?. Academy of management review, 11(3), 656-665.

Becker, B. E., \& Huselid, M. A. 1998. High performance work systems and firm performance: A synthesis of research and managerial implications. Research in Personnel and Human Resource Management, 16: 53-101

Becker, B. E., \& Huselid, M. A. (2006). Strategic human resources management: where do we go from here? Journal of Management, 32(6), 898-925.

Becker, B. E., \& Gerhart, B. 1996. Human resources and organizational performance: Progress and prospects. Academy of Management Journal (Special Issue: Human Resources and Organizational Performance), 39(4): 779-80

Boxall, P., \& Purcell, J. (2000). Strategic human resource management: where have we come from and where should we be going?. International Journal of Management Reviews, 2(2), 183-203.

Brian E. Becker and Mark A. Huselid (2006), "Strategic Human Resource Management: Where Do We Go from Here?", Journal of Management, Vol. 32, (December), pp. 898-925. (2011 JOM Scholarly Impact Award) 
Richard, O. C., \& Johnson, N. B. (2001). Strategic human resource management effectiveness and firm performance. International Journal of Human Resource Management, 12(2), 299-310.

Chadwick, C., \& Cappelli, P. (1999). Alternatives to generic strategy typologies in strategic human resource management. Research in personnel and human resources management, Supplement, 4, 11-29.

Datta, D. K., Guthrie, J. P., \& Wright, P. M. (2005). Human resource management and labor productivity: does industry matter?. Academy of management Journal, 48(1), 135-145.

Dulebohn, J. G. (1995). "The history and evolution of human resource nmanagement." . Handbook of human resource management: , 18-41.

Dyer, L. (1984). Studying human resource strategy: An approach and an agenda. Industrial Relations: A Journal of Economy and Society, 23(2), 156-169.

Dynamic capabilities: what are they? Kathleen M. Eisenhardt ${ }^{*}$ and Jeffrey A. Martin (2000) DOI: 10.1002/1097- Strategic Management Journal Special Issue: The Evolution of Firm Capabilities Volume 21, Issue 10-11,pages 1105-1121, October - November 2000

Gerhart, B. (2005) Human resources and business performance: Findings, unanswered questions, and an alternative approach. Management Review 16, 174-185.

Hofstede, G. (2002). The pitfalls of cross-national survey research: a reply to the article by Spector et al. on the psychometric properties of the Hofstede values survey module 1994. Applied Psychology, 51(1), 170-173.

Hunger, J. D. and Wheelen, T. L. (2003). Essential of Strategic Management Third Edition, New Jersey, USA: Prentice Hall.

Huselid, M. A., Jackson, S. E., \& Schuler, R. S. (1997). Technical and strategic human resources management effectiveness as determinants of firm performance. Academy of Management journal, 40(1), 171-188.

Khalid, M. M., Ashraf, M., \& Rehman, C. A. (2012). Exploring the link between Kirkpatrick (KP) and context, input, process and product (CIPP) training evaluation models, and its effect on training evaluation in public organizations of Pakistan. African Journal of Business Management, 6(1), 274-279.

Khalid, M. M., Ashraf, M. Book Review: The Seven Habits of Highly Effective People; Powerful Lessons in Personal Change (2011). Asian Journal of Business and Management Sciences, Vol. 1, No. 4, pp. 1-6, 2011. 
Khalid, M.M., M., Ilyas, and C.A. Rehman 2014, "HRM Practices and Employee Performance in Public Sector Organizations in Pakistan: An Empirical study" "International Journal of Management Sciences and Business Research". Vol 3 Issue 2-2014

Khalid, M.M., Ashraf, M., Azeem, M., Ahmed, R.I, and Ahmad, H.N. (2012). Proposing a Training Evaluation Strategy to Ensure Training Transfer in Public Sector Organizations in Pakistan: An exploratory Account, International Journal of Human Resource Studies, 2 (1), pp. 111-121.

Lambert, M., Vero, J. and Zimmermann, B. (2012). Vocational training and professional development: a capability perspective, International Journal of Training and Development, 16 (3), pp. 164-182

Kelly, D., \& Amburgey, T. L. (1991). Organizational inertia and momentum: A dynamic model of strategic change. Academy of management journal, 34(3), 591-612.

Khilji, S. E., \& Xiaoyun Wang, (2006). 'Intended'and 'implemented'HRM: the missing linchpin in strategic human resource management research. The International Journal of Human Resource Management, 17(7), 1171-1189.

Lepak, S.A. Snell, 1999 The Human Resource Architecture: Toward a Theory of Human Capital Allocation and Development The Academy of Management Review, 24 (1999), pp. 31-48

Lawler, E., Mohrman, S., and Ledford, A .1992. Employee involvement and total quality management. San Francisco, CA: Jossey-Bass

Lengnick-Hall, C. A., \& Lengnick-Hall, M. L. (1988). Strategic human resources management: A review of the literature and a proposed typology. Academy of management Review, 13(3), 454-470.

McMahan, G. C., Bell, M. P., \& Virick, M. (1998). Strategic human resource management: Employee involvement, diversity, and international issues. Human Resource Management Review, 8(3), 193-214.

Modeling the dynamics of strategic fit: a normative approach to strategic change Edward J. Zajac, ${ }^{1,}$, Matthew S. Kraatz ${ }^{2}$ and Rudi K. F. Bresser ${ }^{3}$ Article first published online: 22 MAR 2000 Strategic Management Journal Volume 21, Issue 4, pages 429-453, April 2000

Pfeffer, J., and Veiga, J. 1999. "Putting people first for organizational success". Academy of Management Journal Of Business And Economics Research Volume 1, Number 192 Executive, 13: 37-48.

Porter, M. 1985. Competitive advantage: Creating and sustaining superior performance. New 
York: Free Press

2014, Vol. 4, No. 3

Richard, O.C. \& Johnson, N.B. "High Performance Work Practices and Human Resource Management Effectiveness: Substitutes or Complements?" Journal of Business Strategies (Fall, 2004)

Ray, G., Barney, J. B., \& Muhanna, W. A. 2004. Capabilities, business processes, and competitive advantage: Choosing the dependent variable in empirical tests of the resource-based view. Strategic Management Journal, 25: 23-37

Truss, C. (2001). Complexities and controversies in linking HRM with organizational outcomes. Journal of Management Studies, 38(8), 1121-1149.

Van Donk, D. \&. (2001) 'Strategic Human Resource Management: A Role of the Human Resource Manager in the Process of Strategy Formation,' . Human Resource Management Review, vol. 2, no. 4, , pp. 299-315.

Wills, T. \&. (1984, August). Relating business strategy to human resource strategy: Some preliminary evidence. Paper presented at the meeting of the Academy of Man agement. Boston.

Wright, P. M., \& Sherman, W. S. (1999). Failing to find fit in strategic human resource management: Theoretical and empirical problems. Research in personnel and human resources management, 4, 53-74.

Wright, P. M., McMahan, G. C., \& McWilliams, A. (1994). Human resources and sustained competitive advantage: a resource-based perspective. International journal of human resource management, 5(2), 301-326.

Wright, P. M., \& McMahan, G. C. (1992). Theoretical perspectives for strategic human resource management. Journal of management, 18(2), 295-320.

Wood, S. \& de Menezes, L. High commitment management in the UK: Evidence from the Workplace Industrial Relations Survey, and Employers' Manpower and Skills Practices Survey. Human Relations, 1998, 51(4), 485-515. 